\title{
Communication
}

\section{Optimum Drilling Parameters of Coir Fiber-Reinforced Polyester Composites}

\author{
Doddapineni Rajeev Kumar, P. S. Sravan Kumar Varma, Boggarapu Nageswara Rao* \\ Department of Mechanical Engineering, Koneru Lakshmaiah University, Vaddeswaram, Guntur, India
}

\section{Email address:}

rajeev.d365@gmail.com (D. R. Kumar), sravankumarvarma.varma1@gmail.com (P. S. S. K. Varma), bnrao52@rediffmail.com (B. N. Rao)

${ }^{*}$ Corresponding author

\section{To cite this article:}

Doddapineni Rajeev Kumar, P. S. Sravan Kumar Varma, Boggarapu Nageswara Rao. Optimum Drilling Parameters of Coir Fiber-Reinforced Polyester Composites. American Journal of Mechanical and Industrial Engineering. Vol. 2, No. 2, 2017, pp. 92-97. doi: 10.11648/j.ajmie.20170202.15

Received: October 15, 2016; Accepted: December 6, 2016; Published: January 21, 2017

\begin{abstract}
This paper presents optimum drilling parameters of coir fiber reinforced polyester composites following the Taguchi design of experiment. A simple multi-objective optimization approach is suggested and presented an efficient prediction methodology to estimate thrust force, torque and tool wear for the identified optimum process parameters.
\end{abstract}

Keywords: Coir Fiber-Reinforced Polyester Composites, Drilling Parameters, Taguchi Method, Thrust Force, Tool Wear, Torque

\section{Introduction}

Natural fiber composites are emerging as realistic alternatives to glass reinforced composites and metals in various engineering applications. Coir, an important lingo-cellulosic fiber from coconut trees has been tested as filler or reinforcement in different composite materials. Satyanarayana et al. [1] have examined structure properties (such as size, density, electrical resistivity, ultimate tensile strength, initial modulus, and percent elongation) of fibers from various parts of the coconut tree. Balan [2] has examined the behavior of geo-textiles with natural fibers. Khedari et al. [3] have examined the possibility of utilization of coconut and durian fibers to reduce the thermal conductivity of mortor to construct wall and other building components. Geethamma et al. [4] have studied dynamic mechanical behavior of short coir fiber reinforced with natural rubber composites. It is noted that composites with poor interfacial bonding tend to dissipate more energy than that with good interfacial bonding. Chaudhury et al. [5] have made investigations on the viability of the thermo-mechanical recycling of post-consumer milk pouches and their use as polymeric matrices for coir fiber reinforced composites. Extensive studies have been made to examine the mechanical and machinability behaviors of coir-fibre reinforced polymeric composite materials [6-14].
Jayabal and Natarajan [6] have considered rectangular composite sheet of $360 \times 360 \times 3 \mathrm{~mm}$ made up of randomly oriented coir fiber composite by the hand layup process. They have fabricated the composite using green husk coir fibre (19\%wt) of length $50 \mathrm{~mm}$ (mixing of $1.5 \mathrm{~g}$ cobalt octoate and $1.5 \mathrm{~g}$ methyl ethyl ketone peroxide per $100 \mathrm{~g}$ polyester resin). Following ASTM-D 638, ASTM-D 790 and ASTM-D 256 standards, specimens are tested and obtained tensile strength of 16.2 MPa, flexural strength of $29.3 \mathrm{MPa}$ and impact strength of $46.2 \mathrm{~J} / \mathrm{m}$. They have performed drilling analysis of coir fiber-reinforced polyester composites adopting Taguchi's approach to arrive optimum parameters namely drill bit diameter, spindle speed and feed rate for obtaining minimum thrust force, torque and tool wear. Careful examination of their analysis indicates that the assignment levels of process parameters and the values specified in $\mathrm{L}_{9}$ orthogonal array are found to be different. The optimum cutting parameters proposed by them are as per the assignment levels of process parameters. The process variables specified in the test runs are not as per the Taguchi's $\mathrm{L}_{9}$ orthogonal array. The mathematical models for the responses (viz., thrust force, torque and tool wear) in terms of the process variables (viz., drill bit diameter, spindle speed and feed rate) are found to be erroneous. Hence, there is a need to reinvestigate this interesting problem and demonstrate the potentiality of the 
Taguchi's design of experiments to trace the optimum process parameters for achieving the desired output response.

In this paper the experimental data of Jayabal and Natarajan [6] are re-arranged as per the orthogonal array of Taguchi approach. A simple and efficient prediction methodology is presented to estimate thrust force, torque and tool wear for the optimum process parameters. The optimum drilling parameters are traced for a randomly oriented coir fiber composite to achieve minimum thrust force, torque and tool wear, which are confirmed through comparison of test results [6].

\section{Taguchi's Design of Experiments and Analysis of Variance}

Most processes have many process parameters influencing the output response. Taguchi has devised a method for analyzing the results from less number of experiments by defining a set of orthogonal arrays [15-18]. Jayabal and Natarajan [6] have conducted a series of experiments using $\mathrm{CNC}$ milling machine to drill the coir-polyester composites. They have used a Kistler-make drill tool dynamometer and recorded the thrust force and torque, whereas a Rapid I machine vision system from Customized Technologies (P) Ltd. has been used to measure the tool wear. They have considered the chip type as another parameter which was produced according to the operating conditions and material properties. It is noted that continuous (C) and discontinuous (D) chip formation was produced for minimum cutting forces and tool wear in HSS tool due to low cutting speed and high feed rate. The chip formation during drilling for the specified conditions is shown in Figure 2 of Ref. [6]. In fact the data in Table 2 of Ref. [6] are not in-line with the assignment levels of process parameters in Table 1 of Ref. [6].

In the present study the assignment levels of process parameters (drill bit diameter, chip- formation, spindle speed and feed rate) are arranged in such a way that the data generated in Ref. [6] will fit the $\mathrm{L}_{9}$ orthogonal array of Taguchi's approach. Table 1 gives the assignment levels of process parameters and the performance/output responses (viz., Thrust force, Torque and Tool wear) for the assigned process parameters and the chip type as per $\mathrm{L}_{9}$ orthogonal array.

Table 1. Performance output responses (viz., thrust force, torque and tool wear) for the assigned process parameters (viz., drill bit diameter, chip formation, spindle speed and feed rate) as per $L_{9}$ orthogonal array.

\begin{tabular}{|c|c|c|c|c|}
\hline Level & Drill bit diameter, d (mm) & Chip formation & Spindle speed, s (rpm) & Feed rate, $\mathrm{f}(\mathrm{mm} / \mathrm{rev})$ \\
\hline 1 & 6 & $\mathrm{C}$ & 600 & 0.05 \\
\hline 2 & 8 & $\mathrm{D}$ & 1200 & 0.35 \\
\hline 3 & 10 & $\mathrm{CD}$ & 1800 & 0.2 \\
\hline
\end{tabular}

Assignment of levels of process parameters

\begin{tabular}{|c|c|c|c|c|c|c|c|}
\hline Test runs & Drill bit diameter (d) & Chip formation & Spindle speed (s) & Feed rate (f) & Thrust force (N) & Torque (N-m) & Tool wear (mm) \\
\hline 1 & 1 & 1 & 1 & 1 & 50 & 2.02 & 0.07 \\
\hline 2 & 1 & 2 & 2 & 2 & 88 & 1.56 & 0.15 \\
\hline 3 & 1 & 3 & 3 & 3 & 58 & 2.94 & 0.2 \\
\hline 4 & 2 & 1 & 2 & 3 & 52 & 2.30 & 0.16 \\
\hline 5 & 2 & 2 & 3 & 1 & 55 & 3.45 & 0.2 \\
\hline 6 & 2 & 3 & 1 & 2 & 32 & 1.02 & 0.03 \\
\hline 7 & 3 & 1 & 3 & 2 & 49 & 3.92 & 0.25 \\
\hline 9 & 3 & 3 & 2 & 1 & 39 & 2.25 & 0.21 \\
\hline
\end{tabular}

Performance output responses

Prior to selection of an orthogonal array, it is customary to estimate the minimum number of experiments from [15-18]:

$$
\text { Ntaguchi }=1+\text { Number of factors } *(\text { Number of levels }-1)=1+4(3-1)=9
$$

Experiments will be conducted as per the level combinations in the selected orthogonal array to record the output response. Mean values of the output response will be evaluated for the level settings. In order to study the sensitiveness of the change in the level of setting, the sum of the squares of deviation of each of the mean value from the grand mean will be evaluated. Percentage contribution is obtained by dividing the sum of the squares of the each process parameter with the total sum of squares. Let $\psi_{i}$ $(i=1$ to $N$ ) be the output responses of $N$ number of experiments. The total sum of squares (TSOS) or total variation is calculated from [15-18]

$$
\operatorname{TSOS}=\sum_{i=1}^{N}\left(\psi_{i}-\bar{\Psi}\right)^{2}
$$

Here $\bar{\Psi}=\left(\sum_{i=1}^{N} \psi_{i}\right) / N$, is the average of the total data.

The sum of squares due to factor $\mathrm{A}(S O S F A)$ is

$$
\text { SOSFA }=\sum_{i=1}^{k_{A}} N_{A i}\left(\bar{\Psi}_{A i}-\bar{\Psi}\right)^{2}
$$


Here $k_{A}$ is the number of levels of factor $A ; \bar{\Psi}_{A i}$ is the average of observations under $A_{i}$ level; and $N_{A i}$ is the number of observations under $A_{i}$ level. Percentage contribution of factor $\mathrm{A}$ to the total variation $(P C F A)$ which may affect the average response is

$$
P C F A=\frac{S O S F A}{T S O S} \times 100
$$

The percentage contribution of each factor to the total variation can be calculated in a similar manner from the sum of squares due to each factor.

The orthogonal array chosen was the $\mathrm{L}_{9}\left(3^{4}\right)$. The plan of experiments in Table 1 is made of 9 tests (array rows) where the second column was assigned to drill bit diameter, the third to the chip formation, the fourth to the spindle speed and the fifth to feed rate. Following Ref.17 the analysis of variance (ANOVA) is performed and the results are presented in Table-2. The optimum cutting parameters in Table 3 are found for the minimum output responses (viz., thrust force, torque and tool wear).

\section{Prediction Methodology}

The process parameters for the optimum thrust force are found to be the drill bit diameter: $8 \mathrm{~mm}$, spindle speed: $600 \mathrm{rpm}$, and feed rate of $0.05 \mathrm{~mm} / \mathrm{rev}$ with $\mathrm{CD}$ type of chip formation. For these process parameters, the thrust force value is not available in Table 1. A confirmation experiment has to be performed to verify the output response (i.e., thrust force). By means of additive law [16] the optimal output response for the desired process parameters can be estimated from

$$
\eta_{o p t}=\eta_{m}+\sum_{j=1}^{n}\left\{\eta_{m}(i, j)-\eta_{m}\right\}
$$

Here $\eta$ is the output response (i.e., thrust force, torque and tool wear) for the process parameters. $\eta_{o p t}=$ Optimum value for output response; $\eta_{m}$ is the overall mean of $\eta$ with 9 test runs; $\eta_{m}(i, j)$ is the mean of $\eta$ at the optimal level ( $\left.i\right)$ and the process parameter $(j)$; and $n$ is number of process parameters.

Table 2. Analysis of variance (ANOVA) for thrust force, torque and tool wear.

\begin{tabular}{llllll}
\hline Factors & 1-Mean & 2-Mean & 3-Mean & Sum of Squares & \% contribution \\
\hline Thrust force (N) & & & & & \\
Drill bit diameter & 65.33 & 46.33 & 52.33 & 566.0 & 26.3 \\
Chip formation & 50.33 & 70.67 & 43 & 1233.1 & 57.4 \\
Spindle speed & 50.33 & 59.67 & 54 & 132.9 & 6.2 \\
Feed rate & 48 & 56.33 & 59.67 & 216.7 & 10.1 \\
Torque (N-m) & & & & & 3.9 \\
Drill bit diameter & 2.17 & 2.26 & 2.58 & 0.2787 & 11.0 \\
Chip formation & 2.75 & 2.19 & 2.07 & 0.7905 & 81.5 \\
Spindle speed & 1.53 & 2.04 & 3.44 & 5.8683 & 3.6 \\
Feed rate & 2.57 & 2.17 & 2.27 & 0.2601 & \\
Tool wear (mm) & & & & \\
Drill bit diameter & 0.14 & 0.13 & 0.2 & $0.9-02$ & 19.8 \\
Chip formation & 0.16 & 0.157 & 0.147 & $0.474-03$ & 1.0 \\
Spindle speed & 0.07 & 0.17 & 0.22 & $0.351-01$ & 77.2 \\
Feed rate & 0.16 & 0.14 & 0.16 & $0.9-03$ & 2.0 \\
\hline
\end{tabular}

Table 3. Optimum cutting parameters for thrust force, torque and tool wear.

\begin{tabular}{llllll}
\hline & Drill bit Diameter $(\mathbf{m m})$ & Chip formation & Spindle speed (rpm) & Feed rate (mm/rev) & Optimum values \\
\hline Thrust force $(\mathrm{N})$ & 8 & $\mathrm{CD}$ & 600 & 0.05 & 23.65 \\
Torque $(\mathrm{Nm})$ & 6 & $\mathrm{CD}$ & 600 & 0.35 & 0.92 \\
Tool wear $(\mathrm{mm})$ & 8 & $\mathrm{CD}$ & 600 & 0.35 & 0.037 \\
\hline
\end{tabular}

In order to examine the validity of the prediction methodology, levels of the process parameters corresponding to the lowest value of the thrust force in Table 1 is considered. For these values one can find from the ANOVA Table-2 that $\eta_{m}(2,1)=46.33 \quad \eta_{m}(3,2)=43 \quad, \quad \eta_{m}(1,3)=50.33 \quad$, $\eta_{m}(2,4)=56.33$ and $\eta_{m}=54.67$. Equation (5) gives 31.98 which is found to be in good agreement with the test result of 32 in Table 1. Regarding the lowest value of torque in Table 1 one can find from the ANOVA Table 2 that $\eta_{m}(2,1)=2.26$ $\eta_{m}(3,2)=2.07, \eta_{m}(1,3)=1.53, \eta_{m}(2,4)=2.17 \quad$ and $\eta_{m}=2.34$. Equation (5) gives 1.01 which is found to be in good agreement with the test result of 1.02 in Table 1. Regarding the lowest value of tool wear in Table-1 one can find from the ANOVA Table 2 that $\eta_{m}(2,1)=0.13$ $\eta_{m}(3,2)=0.147, \quad \eta_{m}(1,3)=0.07, \quad \eta_{m}(2,4)=0.14$ and $\eta_{m}=0.15$. Equation (5) gives 0.037 which is found to be in good agreement with the test result of 0.03 in Table-1. In this way the test data of Table 1 is verified. Comparison of test results with the empirical relation of Jayabal and Natarajan [6] in Figures 1 to 3 indicates the erroneous representation of empirical relations. 


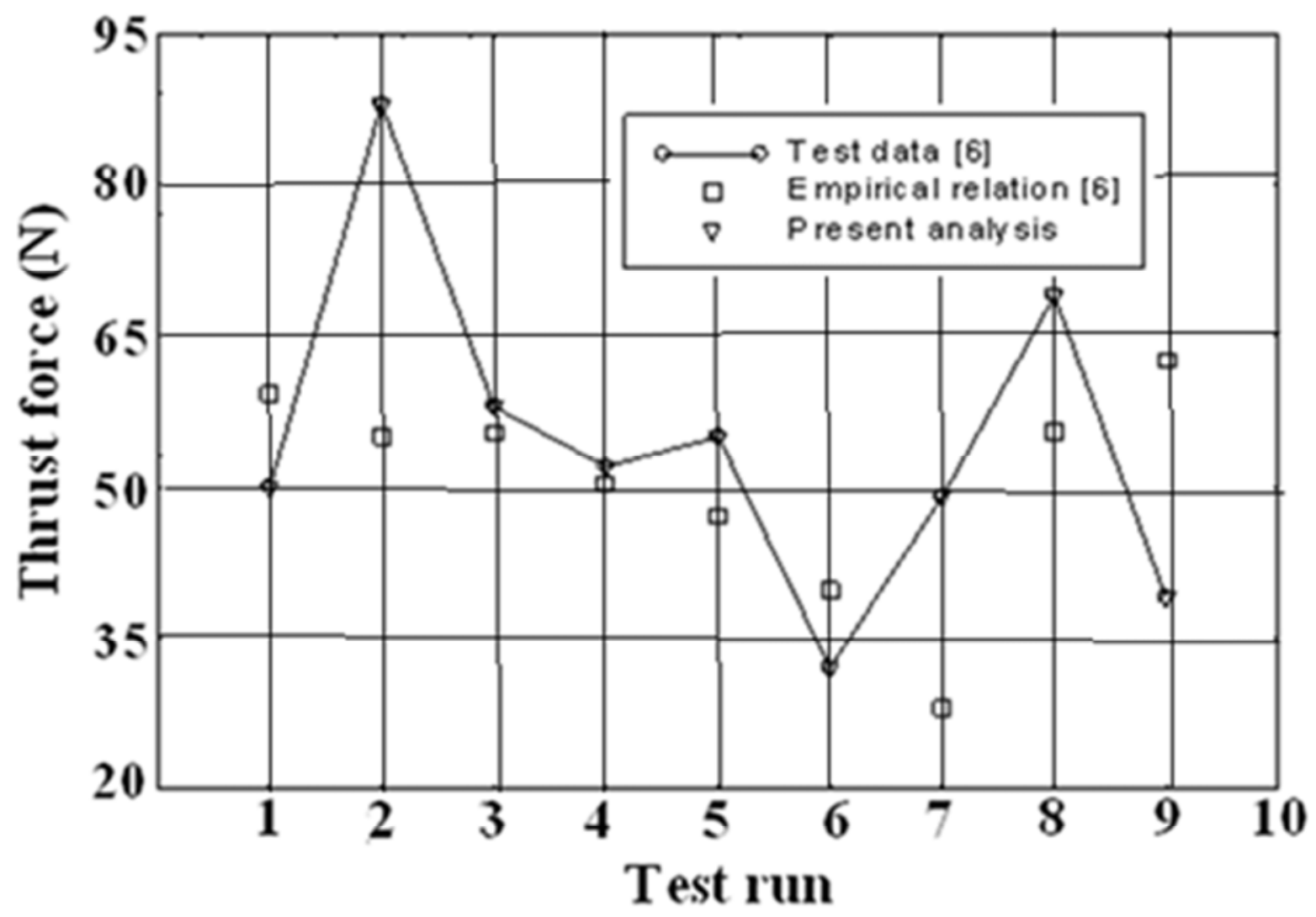

Figure 1. Comparison of predictions with test data of thrust.

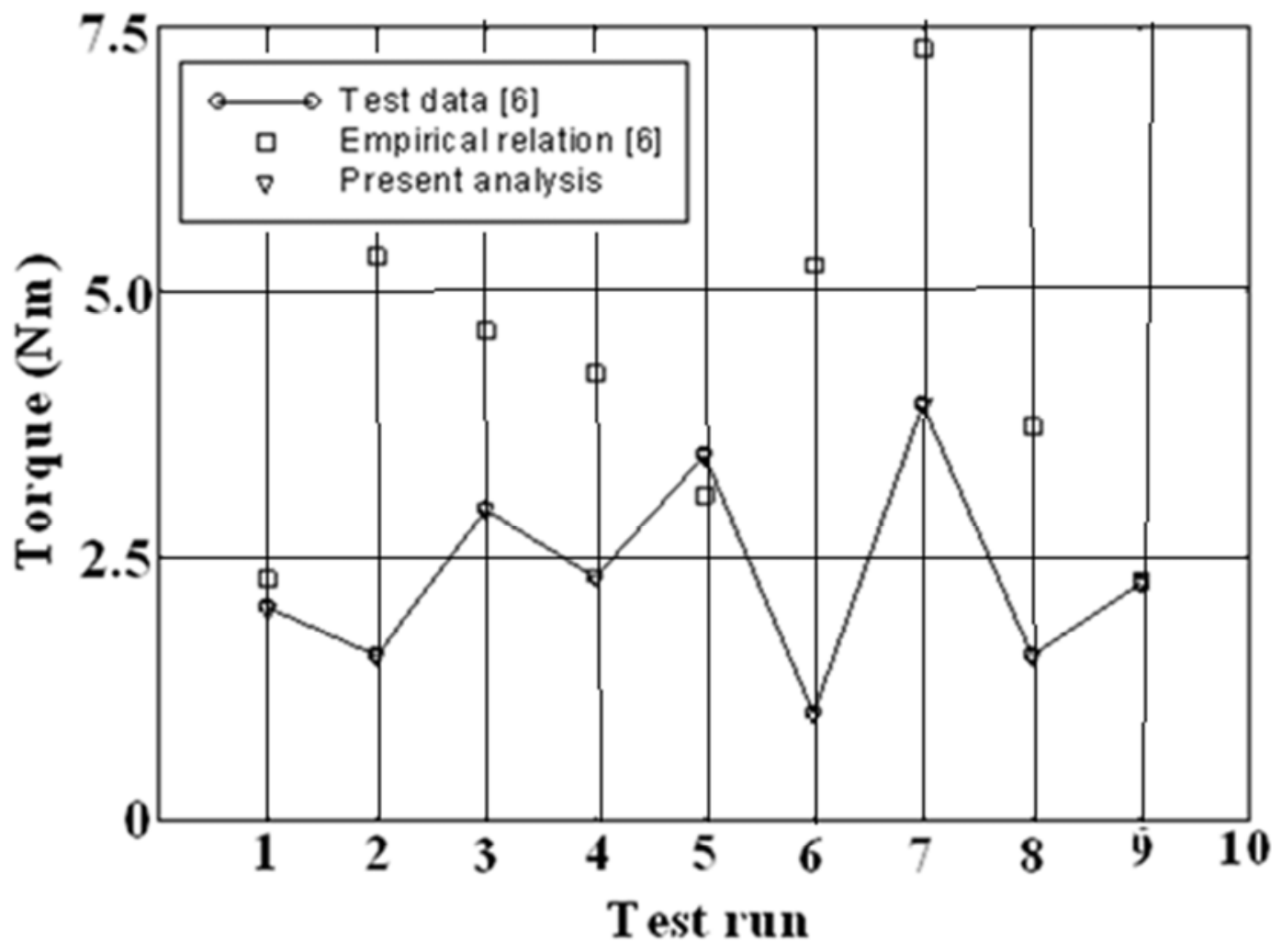

Figure 2. Comparison of predictions with test data of torque. 


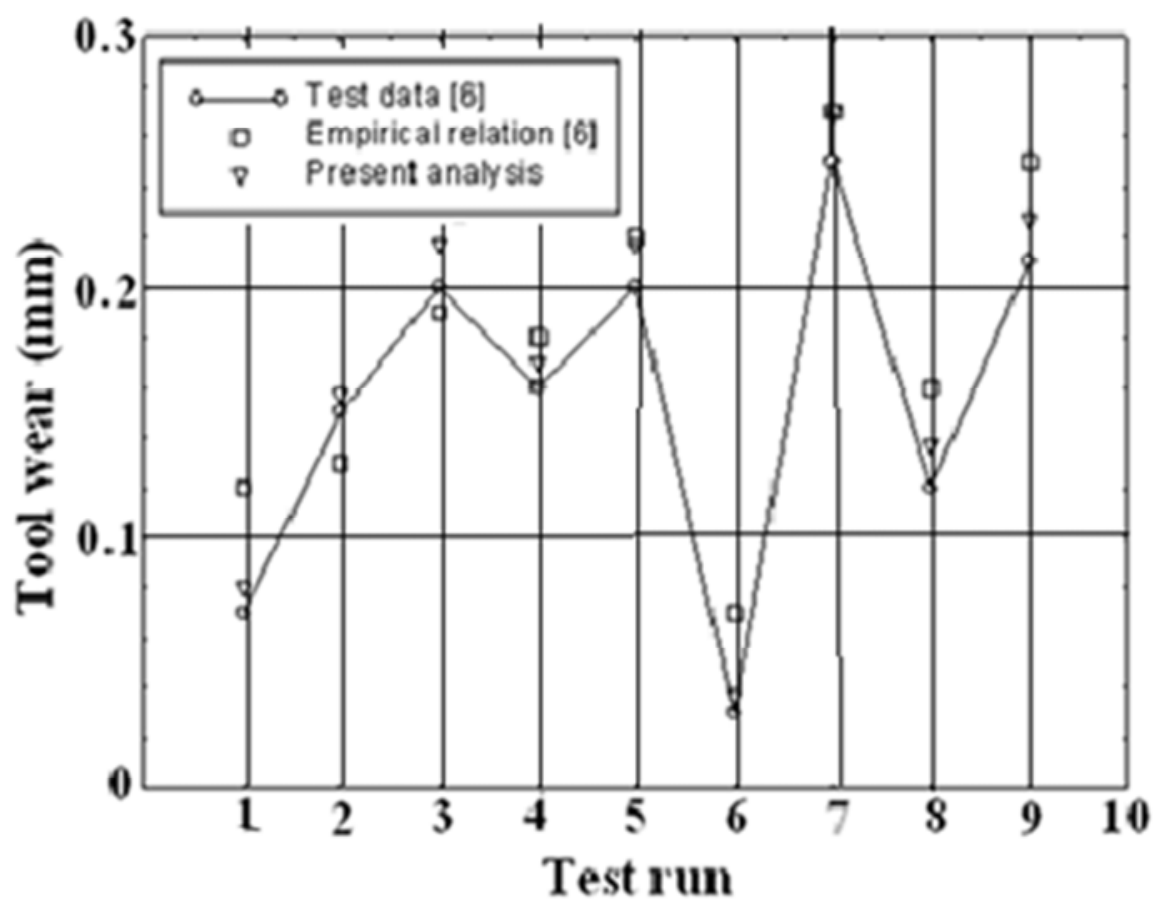

Figure 3. Comparison of predictions with test data of tool-wear.

From equation (4) the optimum values of thrust force, torque and tool wear for the process parameters in Table 3 obtained are $23.65 \mathrm{~N}, 0.92 \mathrm{Nm}$ and $0.037 \mathrm{~mm}$ respectively. The optimal process parameters to achieve minimum output responses are found to be different. To obtain the optimal process parameters to achieve the objective of minimum thrust force, torque and tool wear, a non-dimensional parameter $\zeta$ is introduced as

$$
\varsigma=w_{1} \frac{T h}{(T h)_{\max }}+w_{2} \frac{T q}{(T q)_{\max }}+w_{3} \frac{T w}{(T w)_{\max }}
$$

Here $w_{1}, w_{2}$ and $w_{3}$ are weighing factors, whose sum is unity (i.e., $\left.w_{1}+w_{2}+w_{3}=1\right)$ ). $w_{2}=0$ and $w_{3}=0$ in equation (6) provides the optimum cutting conditions for the thrust force. To have common optimum cutting conditions, equal weights are given (i.e., $w_{1}=w_{2}=w_{3}=1 / 3$ ). The maximum values of Thrust $(T h)_{\max }$, torque $(T q)_{\max }$ and tool wear $(T w)_{\max }$ are estimated by means of the additive law (5) are: $91.33 \mathrm{~N}, 4.32 \mathrm{Nm}$ and $0.29 \mathrm{~mm}$ respectively. The $\zeta$ values for all the 9 test runs of Table 1 are generated and ANOVA is performed on $\zeta$ and obtained the optimum process parameters to achieve minimum $\zeta$ as $8 \mathrm{~mm}$ drill bit diameter, 600rpm spindle speed and $0.35 \mathrm{~mm} / \mathrm{rev}$ feed rate and CD type of chip formation. The thrust force, torque and tool wear corresponding to the optimum process parameters estimated are $32 \mathrm{~N}, 1.02 \mathrm{Nm}$ and $0.03 \mathrm{~mm}$ respectively, which are found to be in good agreement with test results [6].

\section{Concluding Remarks}

Following the concepts of Taguchi design of experiments, the optimum drilling parameters are arrived for a randomly oriented coir fiber composite to achieve minimum thrust force, torque and tool wear. Specimens are tested as per the ASTM-D 638, ASTM-D 790 and ASTM-D 256 standards and obtained tensile strength of 16.2 MPa, flexural strength of 29.3 $\mathrm{MPa}$ and impact strength of $46.2 \mathrm{~J} / \mathrm{m}$. A drill bit of diameter $8 \mathrm{~mm}$, spindle speed: $600 \mathrm{rpm}$ and feed rate of $0.35 \mathrm{~mm} / \mathrm{rev}$ with CD type of chip formation can be preferred for optimizing the thrust force, torque and tool wear while drilling of coir fiber reinforced polyester composites. Optimum values of the thrust force, torque and tool wear are $32 \mathrm{~N}, 1.02 \mathrm{Nm}$ and $0.03 \mathrm{~mm}$ respectively, which are found to be in good agreement with test results [6]. The methodology adopted in the present study is quite simple and the Taguchi's approach works well by generating the data of the test runs as per the orthogonal array.

\section{References}

[1] Satyanarayana K, Pillai CKS, and Sukumaran Pillai K. Structure property studies of fiber from various parts of the coconut tree, Journal of Materials Science 1982; 17: 2453-2462.

[2] Balan K. Studies on engineering behavior and uses of geo textiles with natural fibers, $\mathrm{Ph}$. D. Thesis, Indian Institute of Technology, Delhi, India; 1995.

[3] Khedari J, Suttisonk B, Pratintong N, Hirunlabh J. New lightweight composite construction materials with low thermal conductivity, Cement and Concrete Composites 2001; 23 [1]: $65-70$.

[4] Geethamma VG, Kalaprasad G, Gabriel G, Sabu T. Dynamic mechanical behavior of short coir fiber reinforced natural rubber composites, Composites Part A: Applied Science and Manufacturing 2005; 36[11]: 1499-1506. 
[5] Choudhury A, Kumar S, Adhikari. Recycled milk pouch and virgin low density - Polyethylene/linear low-density polyethylene based coir fiber composites, Journal of Applied Polymer Science 2007; 106: 775-785.

[6] Jayabal S, Natarajan U. Drilling analysis of coir fiber reinforced polyester composites, Bulletin of Material Sciences $2011 ; 34$ [7]: 1563-1567.

[7] Sathiyamurthy S, Syed Abu Thaheer A, Jayabal S. Modelling and optimization of mechanical behaviors of $\mathrm{Al}_{2} \mathrm{O}_{3}-$ coir polyester composites using response surface methodology, Indian Journal of Engineering \& Materials Sciences 2013; 20: 59-67.

[8] Verma D, Gope PC, Shandilya A, Gupta A, Maheswari MK. Coir fibre reinforcement and application in polymer composites: A Review, J. Mater. Environ. Sci. 2013; 4 [2]: 263-276.

[9] Jayabal S, Velumani S, Navaneethakrishnan P, Palanikumar K. Mechanical and machinability behaviors of woven coir fiber-reinforced polyester composite, Fibers and Polymers 2013; 14[9]: 1505-1514. [DOI: 10.1007/s12221-013-1505-5].

[10] Naveen PNE, Yasaswi M. Experimental analysis of coir-fiber reinforced polymer composite materials, International Journal of Mechanical Engineering and Robotics 2013; 2 [1]: 10-18.

[11] Balaji NS, Jayabal S, Kalyana Sundaram S, Rajamuneeswaran S, Suresh P. Delamination analysis in drilling of coir-polyester composites using design of experiments, Advanced Materials Research 2014; 984-985: 185-193. [DOI: 10.4028/www.scientific.net/AMR.984-985.185].

[12] Bharathiraja G, Jayabal S, Prithivirajan R, Sathiyamurthy S. Optimization of mechanical behaviors of bio particulates filled coir-polyester composites using simulated annealing, ARPN Journal of Engineering and Applied Sciences 2014; 9[4]: 487-492.

[13] Okonkwo UC, Chukwunyelu CE, Oweziem BU, Ekuase A. Evaluation and optimization of tensile strength responses of coir fibres reinforced polyester matrix composites (CFRP) using Taguchi robust design, Journal of Minerals and Materials Characterization and Engineering 2015; 3: 225-236. http://dx.doi.org/10.4236/jmmce.2015.34025.

[14] Geetanjali Das, Sandhayarani Biswas. Physical, mechanical and water absorption behavior of coir fiber reinforced epoxy composites filled with $\mathrm{Al}_{2} \mathrm{O}_{3}$ particulates, Materials Science and Engineering 2016; 115: 012012. [DOI: $10.1088 / 1757-899 \mathrm{X} / 115 / 012012]$.

[15] Ranjit KR. A primer on the Taguchi Method, Society of Manufacturing Engineers Dearborn, Michigan: 1990.

[16] Ross PJ. Taguchi Techniques for Quality Engineering, McGraw-Hill, Singapore: 1989.

[17] Srinivasa Rao B, Rudramoorthy P, Srinivas S, Nageswara Rao B. Effect of drilling induced damage on notched tensile strength and pin-bearing strength of woven GFR-epoxy composites, Materials Science \& Engineering A 2008; 472: 347-352 [DOI: 10.1016/j.msea.2007.03.023].

[18] Singaravelu J, Jeyakumar D, Nageswara Rao B. Taguchi's approach for reliability and safety assessments in the stage separation process of a multistage launch vehicle, Reliability Engineering \& System Safety 2009;.94 [10]: 1526-1541. [DOI: 10.1016/j.ress.2009.02.017]. 